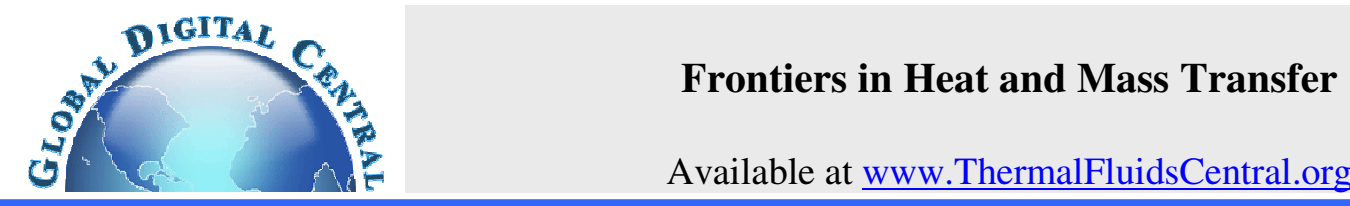

\title{
MODELLING AND SIMULATION OF AU-WATER NANOFLUID FLOW IN WAVY CHANNELS
}

\author{
Suripeddi Srinivas ${ }^{\mathrm{a}}$, Akshay Gupta ${ }^{\mathrm{b} *}$, Ashish Kumar Kandoi ${ }^{\mathrm{b}}$ \\ ${ }^{a}$ Fluid Dynamics Division, School of Advance Sciences, VIT University, Vellore, Tamil Nadu, 632014, India \\ ${ }^{b}$ School of Mechanical and Building Sciences, VIT University, Vellore, Tamil Nadu,632014, India
}

\section{Abstract}

The present work deals with the flow and thermal analysis of nanofluid in the wavy channels. The governing flow equations are solved numerically using CFD package assuming single phase approach. To study the effect of the concentration and size variation of the nanoparticle, the concentration and size are varied from $0 \%-5 \%$ and $25 \mathrm{~nm}-100 \mathrm{~nm}$ respectively over the Reynolds number range of 250-1500 for Au-water nanofluid. The effect on heat transfer enhancement because of corrugation of wavy channel is analyzed on four different shapes (sinusoidal, triangular, trapezoidal and square) channels. The effect of amplitude of the wavy channel is analyzed by varying it from $1 \mathrm{~mm}-3 \mathrm{~mm}$ over the considered Reynolds number range. Also the effect of phase difference $\left(\phi^{*}\right)$ between the top and bottom wavy walls is investigated and its effect on the thermal and flow parameters are reported.

Keywords: Sinusoidal, triangular, trapezoidal, square channels, nano fluid, single phase approach, amplitude and Phase difference.

\section{INTRODUCTION}

For a heat dissipating device used in a heat engine operating between two temperature limits, its efficiency enhances if more heat is extracted from the medium at the sink. For this task passive method of introducing wavy corrugation on the walls of heat exchanger has already been found to be an effective method. The wavy channel helps in creating turbulence in the channel hence leading to better mixing of the fluid and enhancing the heat transfer. Nanotechnology has found its application in multitude streams of engineering ranging from electronics, information technology, energy, medical science, tribology and many more fields of science and technology. Use of nanofluid to enhance the heat transfer characteristics for heat exchanging devices can lead to further cost and size reduction of the heat exchanging devices.

Nanofluid contains extremely minute particles in the size range of nanometers, thus the initial researches suggested them to be homogenous in nature and hence single phase model came into existence. For single phase model approximation, works by Xuan et al. (2000), Brinkman (1952) and Maxwell (1904) acted as the cornerstone in the field which gave formulations for fundamental properties like specific heat, viscosity and conductivity respectively. The Maxwell equation used only the conductivities of the base fluid, nanoparticle and concentration of nanoparticle for the calculation of effective conductivity. There after attempts were made to refine the model by considering particle shape factor in Hamilton-Crosser (1962) model and in Yu and Choi (2003) model they considered a nanolayer surrounding the particle having conductivity greater than base fluid but in all these models the random Brownian motion of the nanoparticle was not considered hence all these models use to underestimate the conductivity. Thus in the present work the thermal conductivity is determined from Patel et al. (2005) model correlation which considers the Brownian motion and diameter of the particle. In recent times the work on multiphase model has narrowed the error between the experimental and numerical results. Lotfi et al. (2010) compared the experimental results of forced convective heat transfer for $\mathrm{Al}_{2} \mathrm{O}_{3}$ in a straight horizontal channel with single phase, twophase Eulerian model and mixture model and concluded that twophase model being a more precise model. Further Kalteh et al. (2011) numerically analyzed the forced laminar flow of $\mathrm{Cu}$-water nanofluid through an isothermally heated micro channel and compared the results of single phase and two-phase Eulerian approach and found that the relative velocity and temperature between the phases was very negligible and the nanoparticle concentration distribution was nearly uniform in Eulerian model. A recent extensive study on multiphase approach by Moraveji et al. (2013) in which the author have compared single phase, VOF, mixture and Eulerian models for the flow of $\mathrm{Al}_{2} \mathrm{O}_{3}$ based nanofluid numerically and found that all multiphase approaches deviates slightly from the experimental results. Yang et al. (2014) have worked on sinusoidal corrugated channel and numerically compared the results of flow of $\mathrm{Cu}$-water, $\mathrm{Al}_{2} \mathrm{O}_{3}$-water and $\mathrm{CuO}$-water by multiphase and single phase approaches and reported the discrepancy with single phase results were within $8 \%$.

The effective thermo physical properties of nanofluid are dependent on the flow regime of nanofluid, concentration and size of the nanoparticles. Some authors (Santra et al., 2009; Davarnejad et al., 2013; Moraveji et al., 2013; Hussein et al, 2013) have showed the effect of concentration and size of nanoparticle in nanofluid and 
found that enhancement due to addition of nanoparticles is significant without significant increase in pressure and also the effect of enhancement is more visible at higher Reynolds number which is associated with higher turbulence associated hence increasing the overall conductivity.

The corrugations on the walls of the channel carrying coolant have found to enhance the heat transfer significantly, Hossain et al. (2007) have compared sinusoidal, triangular and arc shaped channels for heat transfer characteristics with same geometric dimensions, and reported that after the critical Reynolds number which depends on geometric configuration the flow starts mixing up and enhances heat transfer coefficient i.e. after a laminar flow regime when the flow starts to get turbulent. Using nanofluids in corrugated channels can enhance it even further, Pehlivan et al. (2013) studied the effect of corrugation angles and fin height on the heat transfer coefficient for constant heat flux at the boundary walls for a convergent-divergent section and found that by increasing the angle the nusselt number increases. Heidary et al. (2010) discussed the influence of nanoparticles on forced convection in a sinusoidal wavy channel for varying amplitude over a range of particle concentration and Reynolds number for $\mathrm{Cu}$-water nanofluid using $\mathrm{CFD}$ package and reported the increase in enhancement with increasing amplitude, particle concentration and particle size. Ahmed et al. (2011, 2012, and 2013) in series of works have found the similar findings for triangular, trapezoidal and sinusoidal corrugations.

The Nusselt number evaluation can also vary by changing the relative positions of the top and bottom wavy walls. Naphon (2009) researched the effects of wavy plate configuration on temperature and flow distribution on channels of different shaped corrugations like triangular and trapezoidal for different phase orientation of the top and the bottom wavy plate using CFD. Vanaki et al. (2014) reported the heat transfer enhancement and pressure drop in a wavy channel with different phase shifts over turbulent flow regime for $\mathrm{SiO}_{2}$ nanoparticle with different shaped particles-blades, platelets, cylindrical, bricks, and spherical in a sinusoidal channel and concluded the best results for $\mathrm{SiO}_{2}$-ethelyne glycol nanofluid with platelets shaped particles. Jixiang et al. (2012) analyzed the effect of phase shift for sinusoidal channel on flow and heat transfer characteristics over turbulent flow regime. The author also has seen the effect of shear stress and friction factor with different phase shift angles.

Conventionally for increasing the heat transfer in a heat exchanger, one has to use high viscous fluid but that leads to increase in pressure drop across the channel. The effect of corrugated geometry and nanoparticle is such that by adding nanoparticles the enhancement is a lot more significant without significant increase in the pressure drops. Few authors (Arani and Amani ,2012; Kheram ,2011; Fakoor et al., 2013; Aliabadi et al., 2014; Youssef et al., 2012) have suggested the effect of geometry of the channel and nanoparticle size and concentration on the pressure drop across the channel. Vatani et al. (2013) discussed the effect on heat transfer enhancement and friction factor for varying nanoparticle type, size and concentration for turbulent flow in triangular, square and arc shaped ribbed channel.

In the present work, an exhaustive study is performed for four different corrugated wavy-shaped channels-sinusoidal, square, triangular and trapezoidal with nanofluid flowing through it. The analyses are done in Ansys Fluent CFD package using single phase approach. The effect of nanoparticle size and particle concentration is observed over a Reynolds number range of 250-1500 with Au nanoparticles. Further, the effect of geometrical parameters on heat transfer and pressure drop is carried out for different wavy amplitude and phase difference $\left(\phi^{*}\right)$ for different shaped corrugations.

\section{MATHEMATICAL MODELLING}

\subsection{Problem Statement}

In the present problem a single phase model assumption is used to model nanofluid flow in different wavy-shaped channels. The physical model and geometric configuration for the problem is shown in Fig 6. It consists of a straight channel with $20 \mathrm{~mm}$ hydraulic diameter and two parallel isothermally heated walls of $80 \mathrm{~mm}$ length at the entrance for the flow to be fully developed in the wavy part. Six wave numbers of wavelength $22 \mathrm{~mm}$ are taken in the wavy channel which is also the heated section. Total length of the channel is $400 \mathrm{~mm}$. In the analyses the amplitude of the wavy part is varied as $1 \mathrm{~mm}, 2 \mathrm{~mm}$ and $3 \mathrm{~mm}$ and the $\phi^{*}$ of $0^{\circ}, 45^{\circ}, 90^{\circ}, 135^{\circ}$ and $180^{\circ}$ is applied between the top and bottom wavy parts.

\subsection{Governing Equation}

The governing equation in non-dimensional for while considering single phase approach for the mixture of base fluid and nanoparticles are as follows (Santra et al., 2009; 33):

Continuity Equation:

$\frac{\partial U}{\partial X}+\frac{\partial V}{\partial Y}=0$

X-Momentum:

$$
\frac{\partial U}{\partial \tau}+U \frac{\partial U}{\partial X}+V \frac{\partial V}{\partial Y}=-\frac{\partial P}{\partial X}+\frac{1}{\operatorname{Re}} \frac{\rho_{f}}{\rho_{n f}} \frac{1}{(1-\phi)^{2.5}}\left[\frac{\partial^{2} U}{\partial X^{2}}+\frac{\partial^{2} U}{\partial Y^{2}}\right]
$$

Y-Momentum:

$$
\frac{\partial V}{\partial \tau}+U \frac{\partial V}{\partial X}+V \frac{\partial V}{\partial Y}=-\frac{\partial P}{\partial Y}+\frac{1}{\operatorname{Re}} \frac{\rho_{f}}{\rho_{n f}} \frac{1}{(1-\phi)^{2.5}}\left[\frac{\partial^{2} V}{\partial X^{2}}+\frac{\partial^{2} V}{\partial Y^{2}}\right]
$$

Energy:

$$
\frac{\partial \theta}{\partial \tau}+U \frac{\partial \theta}{\partial X}+V \frac{\partial \theta}{\partial Y}=\frac{1}{\operatorname{RePr}} \frac{K_{n f}}{K_{f}} \frac{\left(\rho C_{P}\right)_{f}}{\left(\rho C_{P}\right)_{n f}}\left[\frac{\partial^{2} \theta}{\partial X^{2}}+\frac{\partial^{2} \theta}{\partial Y^{2}}\right]
$$

The non-dimensional parameters are:

$$
\begin{array}{lll}
X=\frac{x}{D_{h}}, & Y=\frac{y}{D_{h}}, & U=\frac{u}{u_{i n}}, \\
V=\frac{v}{u_{i n}}, & \theta=\frac{T-T_{i n}}{T_{w}-T_{i n}}, & P=\frac{p}{\rho_{f} \mu_{f}^{2}} \\
\tau=\frac{t u_{i n}}{D_{h}}, & \operatorname{Re}=\frac{\rho_{f} u_{i n} D_{h}}{\mu_{f}}, & \operatorname{Pr}=\frac{u_{f} C_{p f}}{k_{f}}
\end{array}
$$

The solution of the governing equations gives the flow and temperature field which are used to calculate the Nusselt number for the flow as follows. The local and the average Nusselt number for the corrugated walls are defined as follows (Santra et al., 2009).

$$
\begin{aligned}
& N u_{l}=\frac{1}{x_{e}-x_{s}} \int_{x_{s}}^{x_{e}} N u_{x} d x \\
& N u_{x}=\frac{h_{x} D_{h}}{k_{n f}}=\left|-\frac{k_{f}}{k_{n f}} \frac{\partial \theta}{\partial Y}\right|_{x, 0}
\end{aligned}
$$


The pressure drop for the flow in the corrugated channel is calculated as:

$\Delta P=f \frac{\left(\mathrm{X}_{e}-\mathrm{X}_{s}\right)}{D_{h}} \frac{\rho_{n f} u_{i n}^{2}}{2}$

\subsection{Thermo physical properties of nanofluid}

Thermo physical properties of nanofluid are calculated from the Single phase model equations and are used in the governing equations:

Viscosity (Brinkman, 1952), Brinkman's model has been used:

$\mu_{n f}=\frac{\mu_{f}}{(1-\phi)^{2.5}}$

Density:

$\rho=(1-\phi) \rho_{f}+\phi \rho_{p}$

Specific Heat (Xuan et al., 2000):

$\left(\rho C_{p}\right)_{n f}=(1-\phi)\left(\rho C_{p}\right)_{f}+\phi\left(\rho C_{p}\right)_{p}$

Conductivity (Patel et al., 2005):

$\frac{K_{e f f}}{K_{f}}=1+\frac{K_{p} A_{p}}{K_{f} A_{f}}+c K_{p} P e \frac{A_{p}}{K_{f} A_{f}}$

Where:

$$
\frac{A_{p}}{A_{f}}=\frac{d_{f}}{d p} \frac{\phi}{(1-\phi)} \quad P e=\frac{u_{p} d_{p}}{a_{f}}
$$

Where $u_{p}$ is the Brownian motion velocity of the particles which is defined as follows:

$u_{p}=\frac{2 K_{p} T}{\pi \mu_{f} d_{p}^{2}}$

\subsection{Boundary Conditions}

Boundary Conditions are as follows:

1) At the inlet:

$$
u=u_{i n}, v=0, \mathrm{~T}=\mathrm{T}_{i n}=293
$$

2) Along the heated Section:

$$
u=v=0, T_{w}=303 \mathrm{~K}
$$

3) At the Straight section:

$$
u=v=0 \text { (no slip), } \mathrm{T}=\mathrm{T}_{i n}
$$

4) Outlet boundary:

$$
\frac{\partial u}{\partial x}=\frac{\partial v}{\partial x}=\frac{\partial T}{\partial x}=0
$$

\section{NUMERICAL TECHNIQUE}

After the conversion of non-dimensional governing equations from Cartesian to computational domain, the discretization of timeindependent incompressible Navier-Stokes governing equations was done using the finite-volume method (FVM). The diffusion term in the momentum and energy equations is approximated by secondorder central difference and QUICK Scheme is adopted for the convective terms. The flow field was solved using the SIMPLEC algorithm this is an iterative solution procedure where the computation is initialized by guessing the pressure field. Then, the momentum equation is solved to determine the velocity components. The pressure is updated using the continuity equation. The convergence criteria for all the variables are set as $10^{-5}$.The mesh independency test was carried for four different grid sizes $560 \times 30$, $653 \times 40,738 \times 50$ and $836 \times 60$ for water. Nusselt number and heat transfer coefficient (HTC) were found to vary by $0.3672 \%$ and $0.3653 \%$ respectively, thus indicating that results are independent of mesh size. For the optimal CPU time for computation in simulations, grid size of 738 X 50 was used for the CFD simulations.

\section{VALIDATION}

For validating the numerical method and the mathematical model used for the analysis, the results of the flow of $\mathrm{Cu}$-water nanofluid in straight channel was compared with the work of Santra et al. (2009), as can be observed from Fig 1 and the results shows a slight deviation at $\operatorname{Re}=500$ and $\mathrm{Re}=1500$. Figure 2 shows the comparison of results obtained for Nusselt number in the present study from numerical simulation with that of Yang et al. (2014) for the flow of water through a sinusoidal channel with $3 \mathrm{~mm}$ amplitude and $180^{\circ}$ phase difference for water.

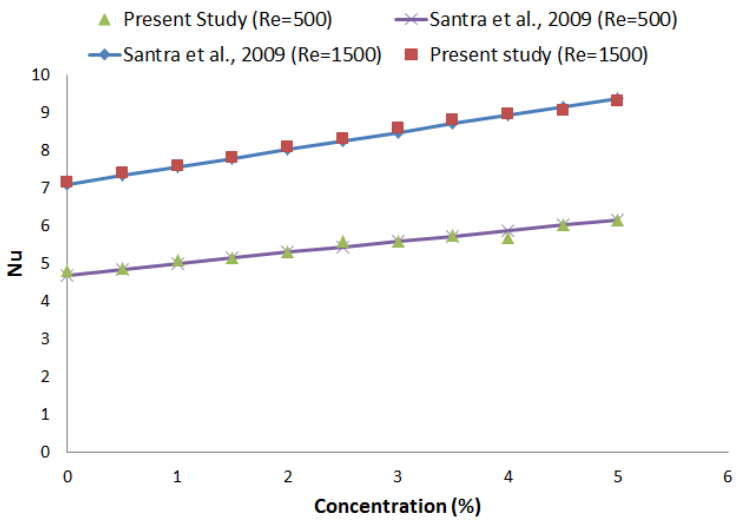

Fig. 1 Nusselt number at different concentrations

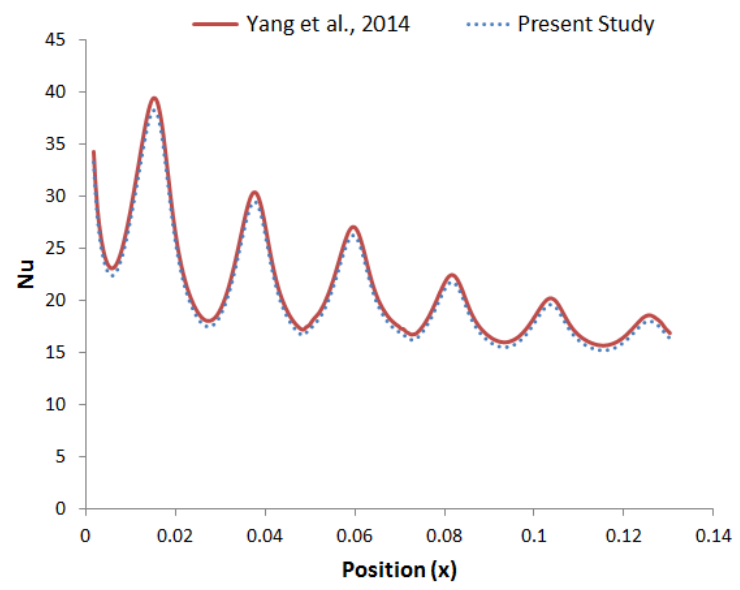

Fig. 2 Nusselt number at different sections of a sinusoidal channel

\section{RESULT AND DISCUSSIONS}

The analysis of the effect of nanoparticle concentration, size and geometrical variations were carried out for four different shaped 
channels-sinusoidal, triangular, trapezoidal and square for Au-water nanofluid. From the work of Kalteh (2013), who compared the performance of nine different water based nanofluids $\left(\mathrm{SiO}_{2}, \mathrm{TiO}_{2}\right.$, $\mathrm{CuO}, \mathrm{Al}_{2} \mathrm{O}_{3}, \mathrm{Fe}, \mathrm{Cu}, \mathrm{Ag}, \mathrm{Au}$ and diamond) in a straight channel at $\mathrm{Re}=100$ and $1 \%$ concentration a comparative performance of different nanofluids can be understood,. Au-water nanofluid is selected for the present study as $\mathrm{Au}$ is widely known for its biocompatible properties (Bogliotti et al., 2011; Arnida et al., 2011.)

\subsection{Effect of nanoparticle size and concentration}

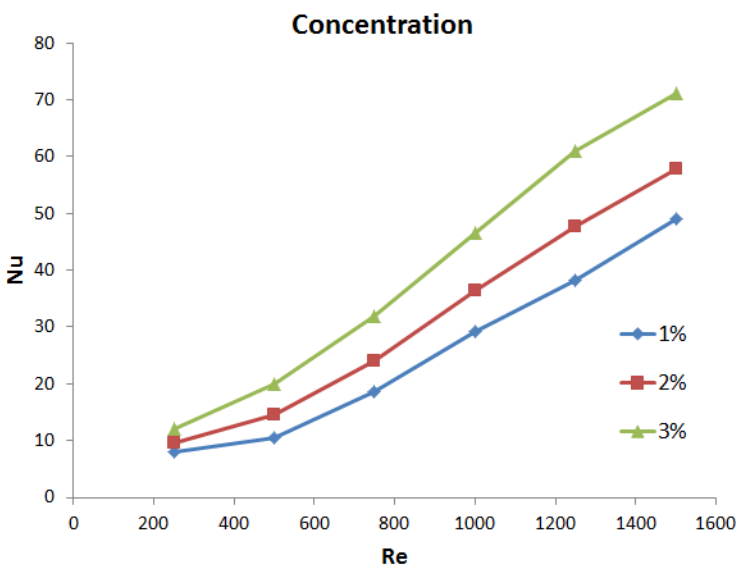

Fig. 3 Effect of nanoparticle concentration on Nusselt number

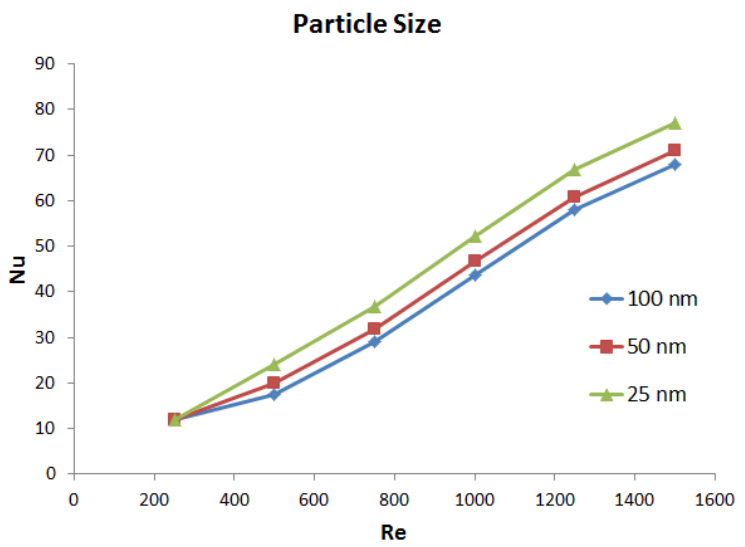

Fig. 4 Effect of nanoparticle size on Nusselt number.

Figure 3 is depicting the effect of varying $\mathrm{Au}$ particle concentration as 1\%,3\% and 5\% and Fig 4 is depicting the effect of Au nanoparticle size as $25 \mathrm{~nm}, 50 \mathrm{~nm}$ and $100 \mathrm{~nm}$ on Nusselt number in a sinusoidal channel with $180^{\circ}$ phase difference and $3 \mathrm{~mm}$ amplitude for laminar flow regime with Reynolds number variation of 250-1500. The effect of increasing the concentration resulted in increase of Nusselt number due to increase in thermal conductivity of the nanofluid. It is observed that the difference between the $1 \%$ and $5 \%$ concentration for Nusselt number at $\mathrm{Re}=250$ is just 3.85 and this difference grows to 22 at $R e=1500$, this shows that the enhancement at low Reynolds number is not reflected as clearly as at higher Reynolds number. This is because of randomness of the molecular motion causing the conductivity to increase and hence the enhancement at higher Reynolds number.

The effect of nanoparticle size variation can be seen in Fig 4 which suggests that the Nusselt number increases by decreasing the particle size as obvious because of increase in conductivity of nanofluid as a result of increased surface area and Brownian motion. It is observed that the difference of Nusselt number between the 25 $\mathrm{nm}$ and $100 \mathrm{~nm} \mathrm{Au}$ nanoparticle size at $\mathrm{Re}=250$ is 0.21 and this difference grows to 8.94 at $\mathrm{Re}=1500$, this confirms that the enhancement at low Reynolds number is not reflected as clearly as at higher Reynolds number due to the effect of turbulence which increases the conductivity and hence the enhancement at higher Reynolds number.

\subsection{Effect of amplitude on different shaped channels}

The effects of amplitude of corrugations on different shaped wavychannels are shown in Fig 5, it can be seen that as we increase the amplitude of the wavy channel, the turbulence and flow reversal increases. For the comparison of various geometries at $1 \mathrm{~mm}$ amplitude, from Fig 7 (a), it can be observed that the Nusselt number and pressure drop for a square channel is throughout greater than other shaped channels irrespective of the Reynolds number. The difference of Nusselt number between square and other shaped channels at lower Reynolds number is more than at higher Reynolds number, because in square channel, higher turbulence can be generated at lower Reynolds number itself whereas for other geometries the enhancement due to turbulence is generated at relatively higher Reynolds number. As we increase the amplitude it can be observed that at certain Reynolds number the enhancement in the heat transfer for other geometries goes beyond that of square but the pressure drop across the channel is always the highest for square and least for triangular and the plots of pressure drop are seen to diverge out more at higher Reynolds number with the increase of amplitude i.e. increase in pressure drop for square shaped corrugation at higher Reynolds number is more than the other channels. At higher Reynolds number thus it is favorable to operate at $3 \mathrm{~mm}$ amplitude in triangular corrugated channel so as to get the maximum heat transfer enhancement and least pressure drop.

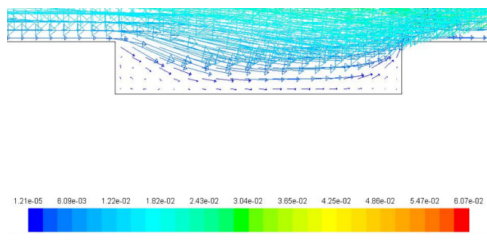

(a)

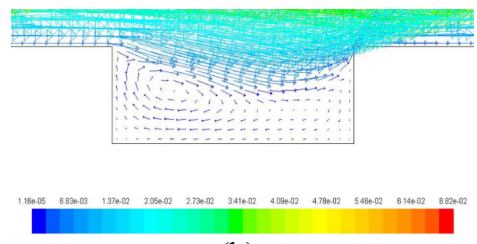

(b)

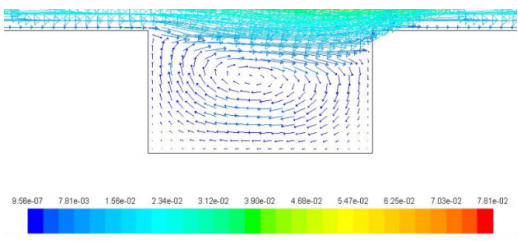

(c)

Fig. 5 Velocity vector for square channel at different amplitude at $\mathrm{Re}=1500$ : (a) $1 \mathrm{~mm}$ (b) $2 \mathrm{~mm}$ (c) $3 \mathrm{~mm}$ 


\subsection{Effect of phase difference on different shaped channels}

The effect of phase difference $\left(\phi^{*}\right)$ between the top and the bottom waves of the corrugated channel is reported in Fig 8, Fig 9, Fig 10 and Fig 11. Five different phase shifts of $0^{\circ}, 45^{\circ}, 90^{\circ}, 135^{\circ}$ and $180^{\circ}$ are considered for the analysis. As can be observed in Fig 8, the Nusselt number is minimum and pressure drop is maximum at $90^{\circ}$ phase shift angle suggesting that it is not favorable for the heat dissipating devices such as radiators to operate at this particular phase shift angle.

Also as the phase angle is changing the maximum and minimum velocities across the section is changing because of the change in the effective cross section for the flow as can be seen in Fig 11, thus affecting the heat transfer characteristics of the channel.
In Fig 9 and Fig 10, the comparison for all the geometries for various Reynolds number with all the phase difference angles are presented. The observations are:

I. At $0^{\circ} \phi^{*}$ the Nusselt number is maximum for trapezoidal and least for square throughout the flow regime whereas the pressure drop is maximum for square and minimum for triangular thus suggesting that Square being the worse possible option for this orientation.

II. At $45^{\circ}, 90^{\circ}$ and $135^{\circ} \phi^{*}$ it is observed that throughout the Reynolds number range, triangular channel gives least pressure drop and maximum Nusselt number whereas square gives maximum pressure drop and minimum Nusselt number.

III. At $180^{\circ}$, the Nusselt number as well as the pressure drop is maximum for square geometry. Pressure drop is least for triangular and the Nusselt number is least for trapezoidal.
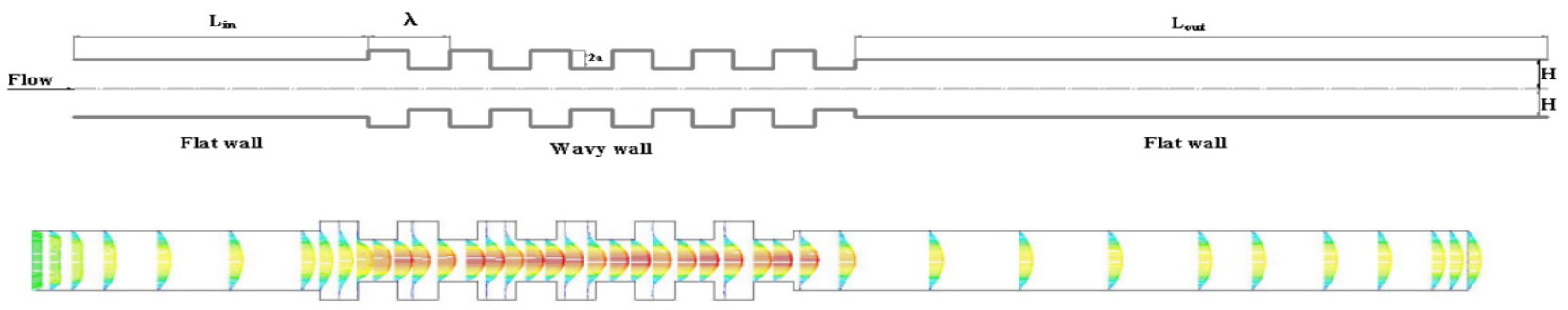

Fig. 6 Schematic diagram of the present problem

$1 \mathrm{~mm}$ Amplitude

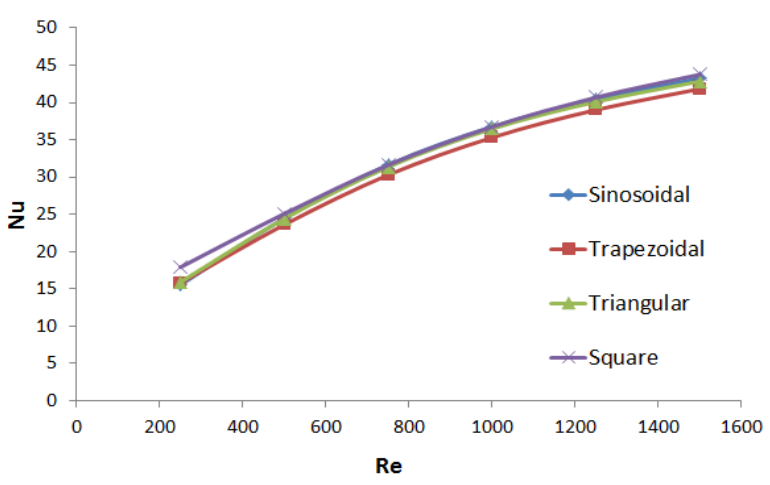

(a)

$2 \mathrm{~mm}$ Amplitude

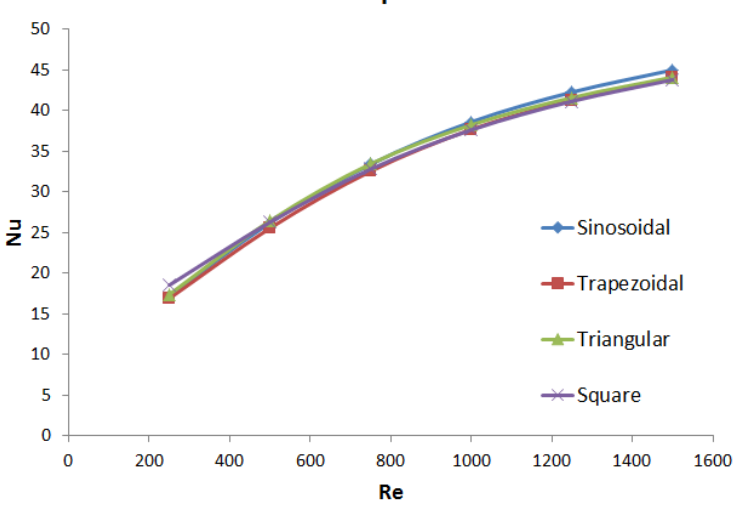

$1 \mathrm{~mm}$ Amplitude

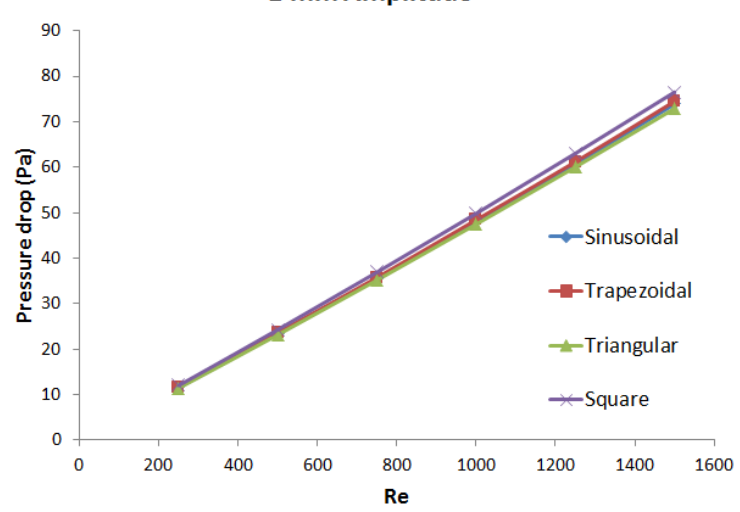

$2 \mathrm{~mm}$ Amplitude

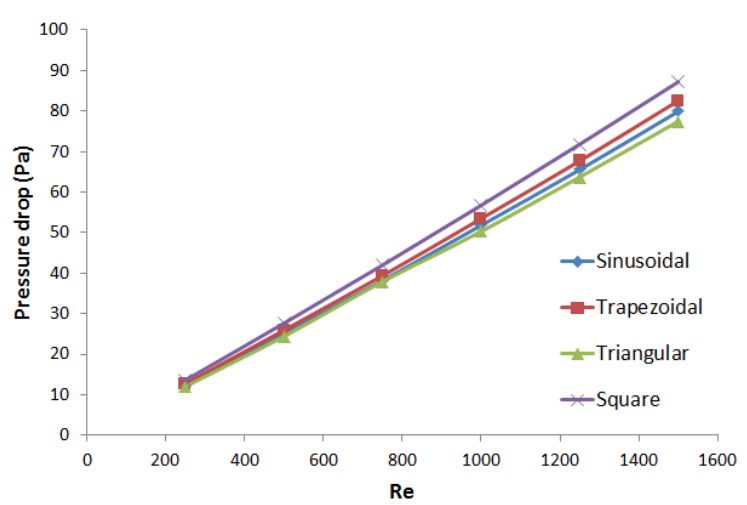


3 mm Amplitude

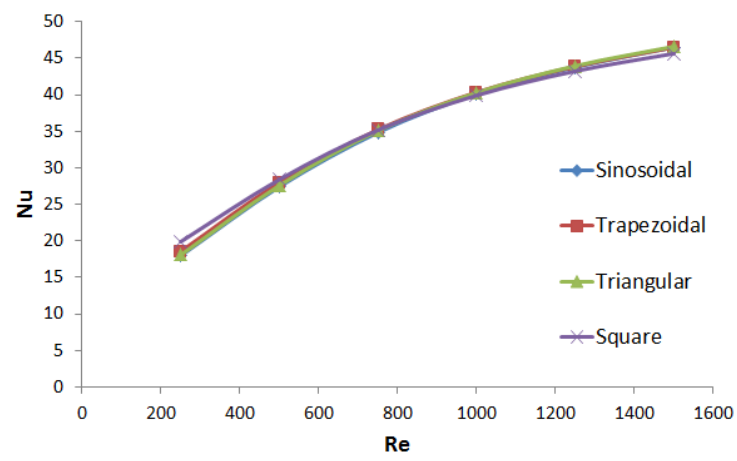

$3 \mathrm{~mm}$ Amplitude

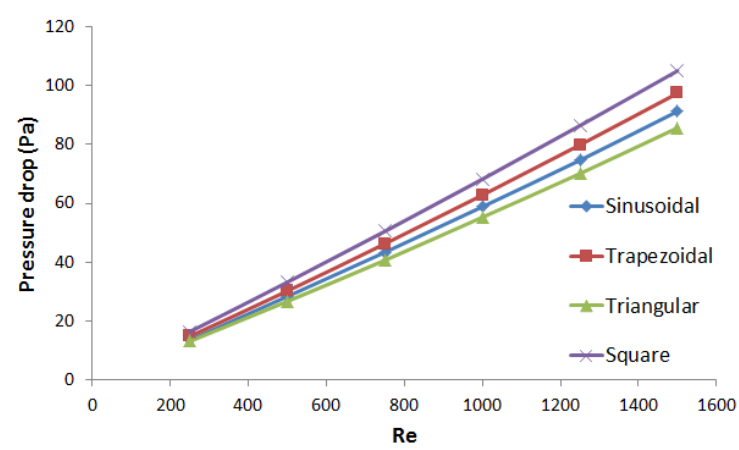

(c)

Fig. 7 Nusselt number and pressure drop (Pa) variation for (a) $1 \mathrm{~mm}$ (b) $2 \mathrm{~mm}$ (c) $3 \mathrm{~mm}$ amplitude.
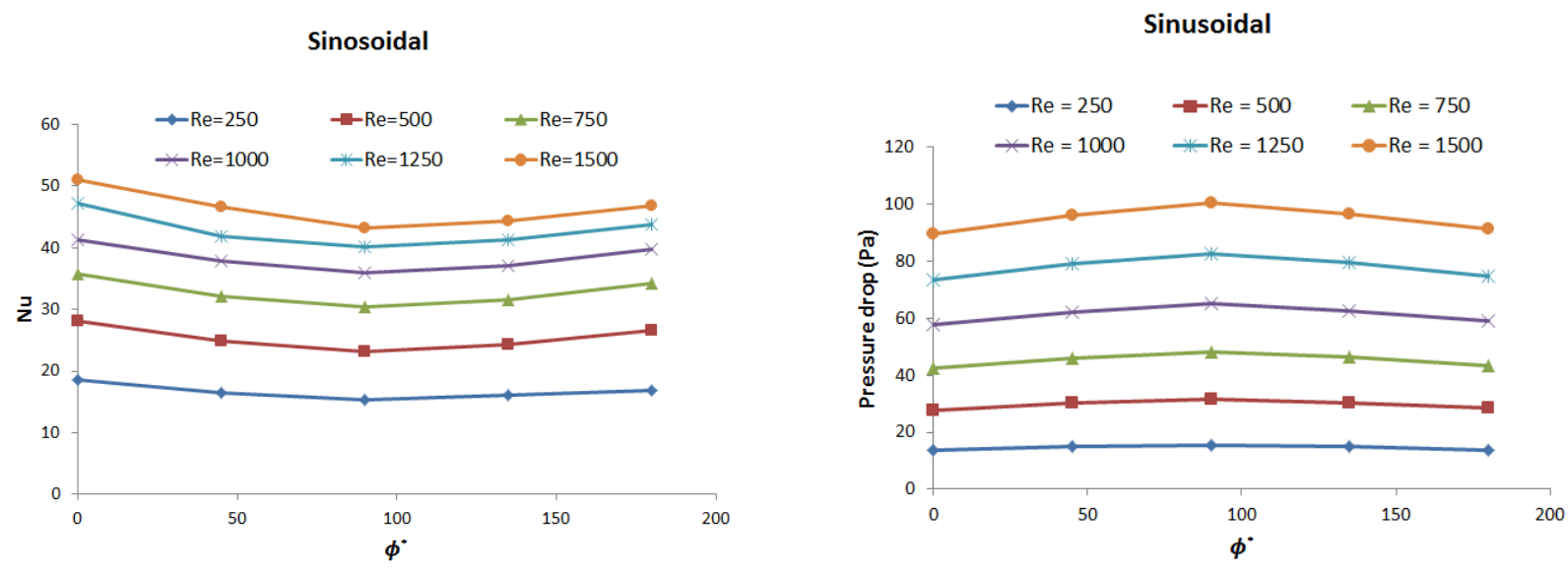

(a)
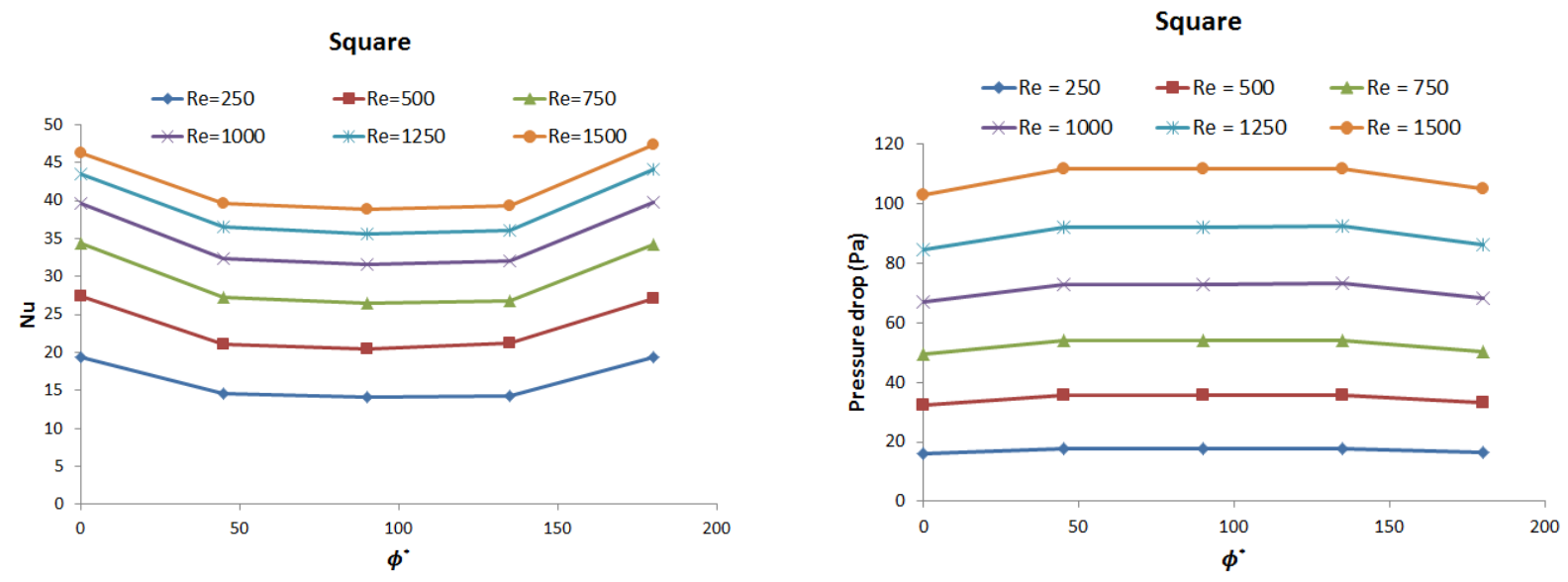

(b) 

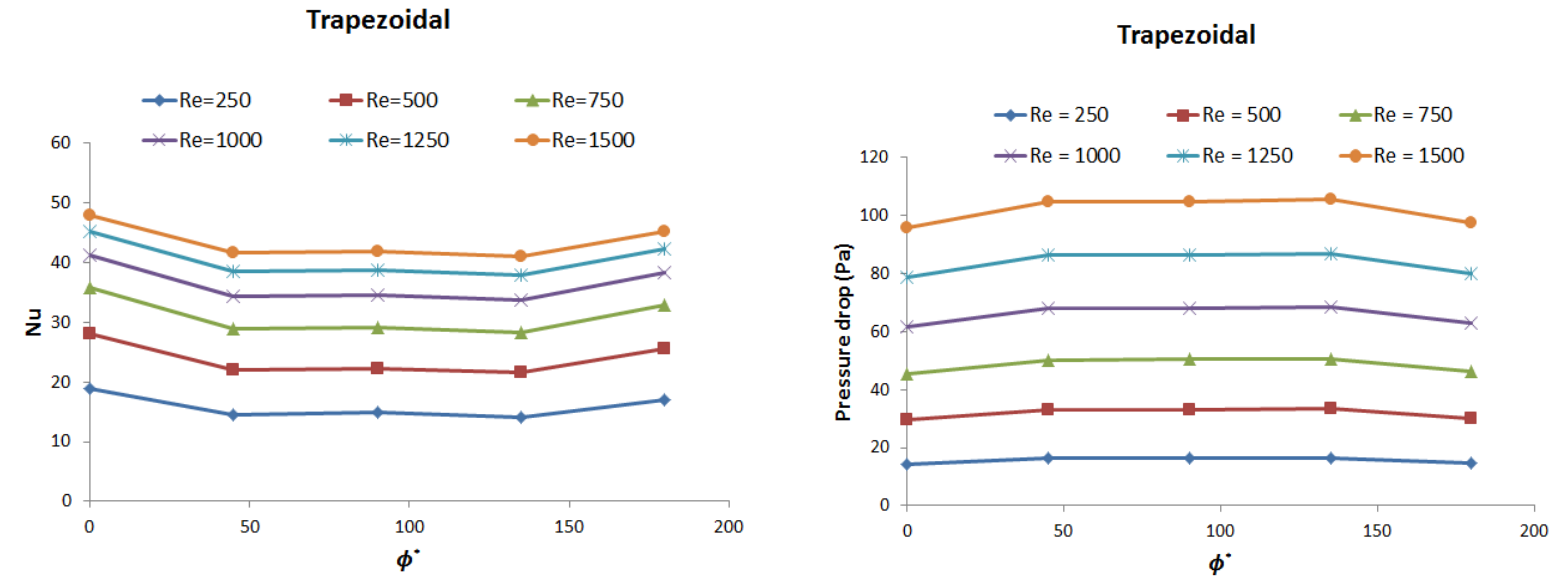

(c)
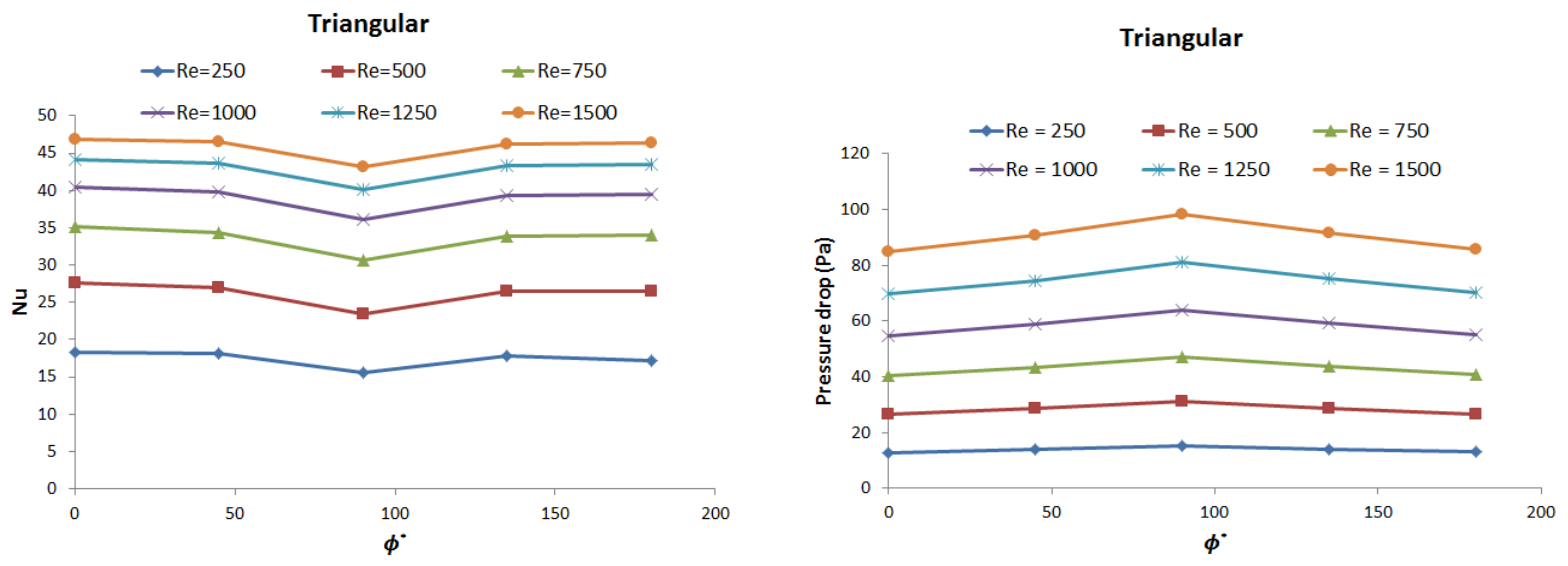

(d)

Fig. 8 Nusselt number and pressure drop (Pa) variation with $\phi^{*}$ (a) Sinusoidal (b) Square (c) Trapezoidal (d) Triangular

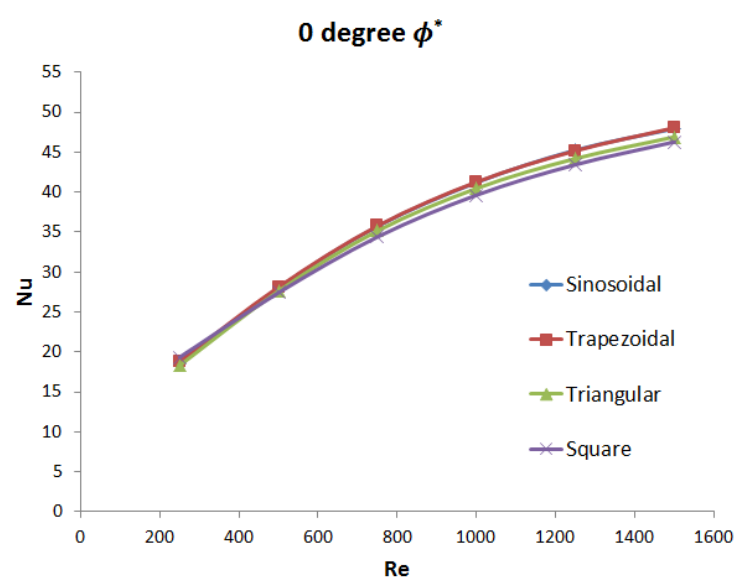

(a)
45 degree $\phi^{*}$

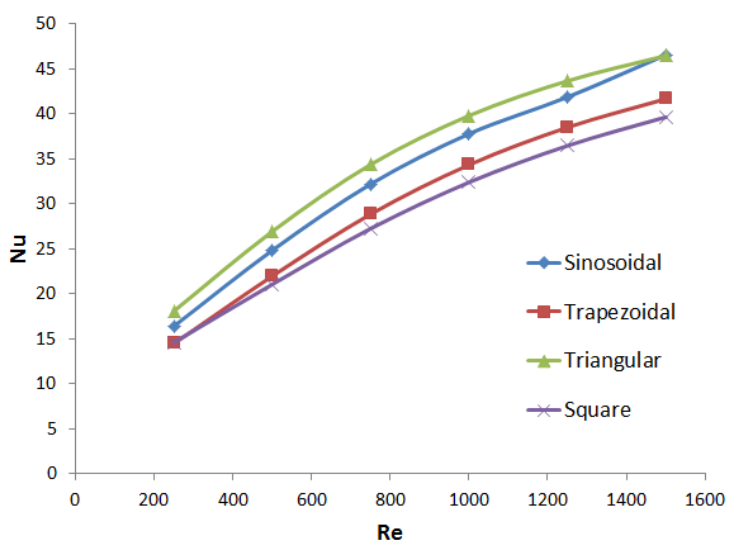

(b) 


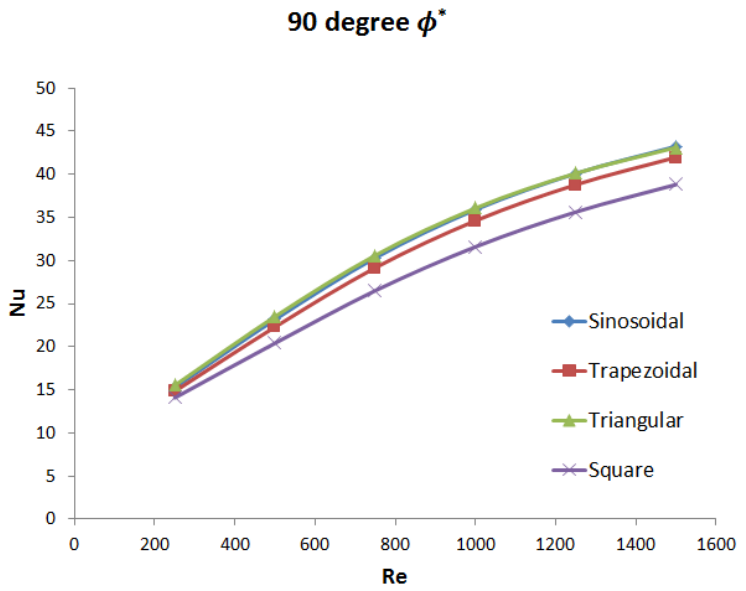

(c)

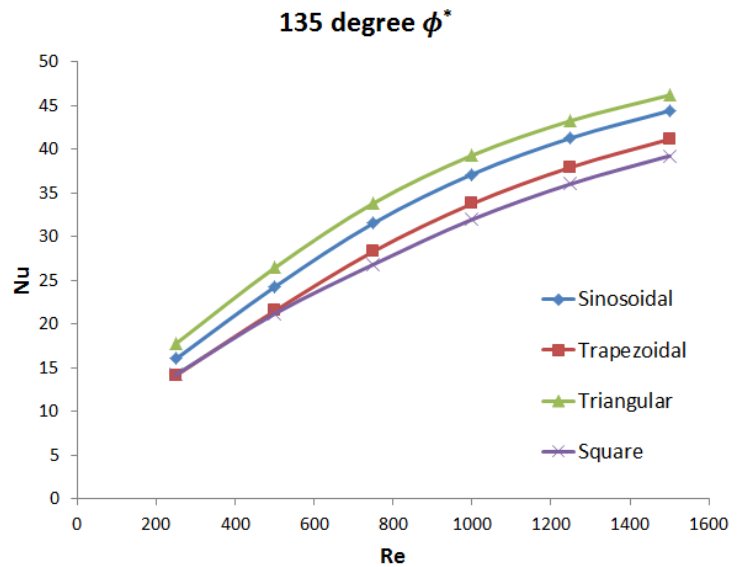

(d)

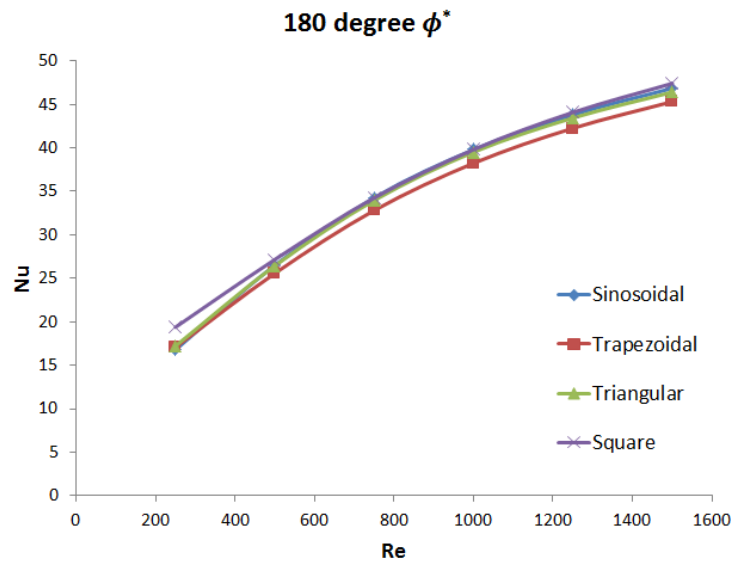

(e)

Fig. 9 Nusselt number variation for different geometries at different $\phi^{*}$ : (a) $0^{\circ}$ (b) $45^{\circ}$ (c) $90^{\circ}$ (d) $135^{\circ}$ (e) $180^{\circ}$

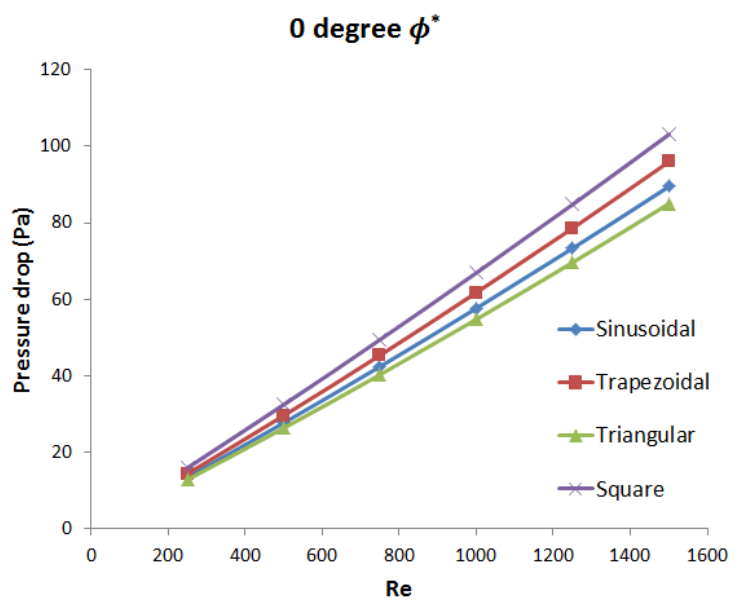

(a)

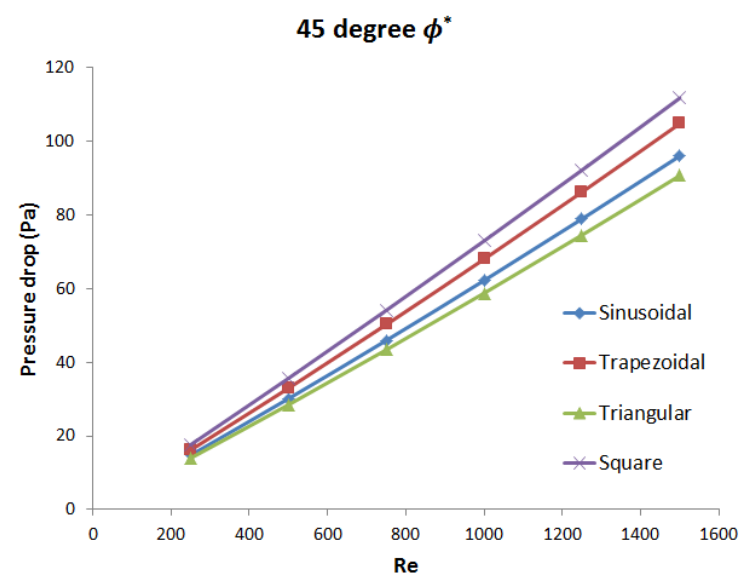

(b) 


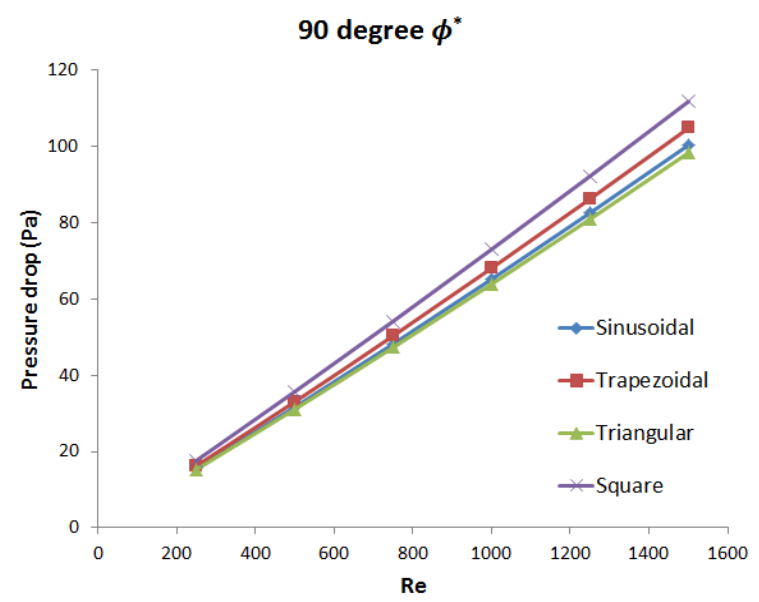

(c)

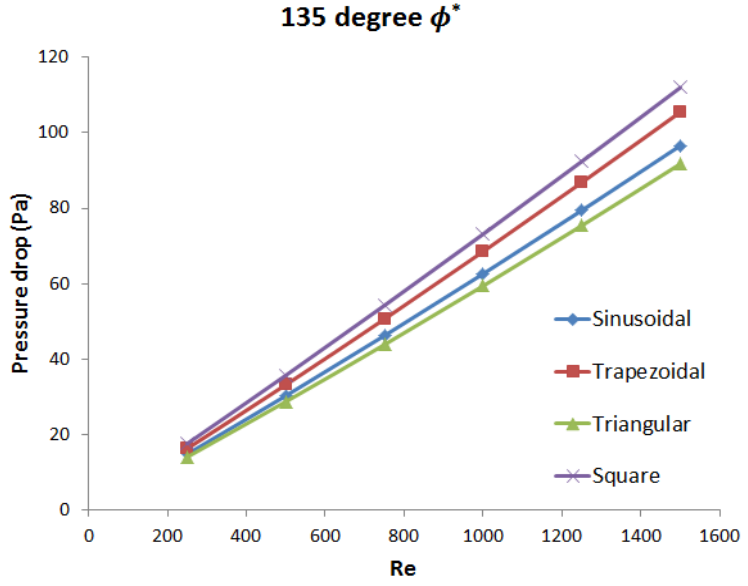

(d)

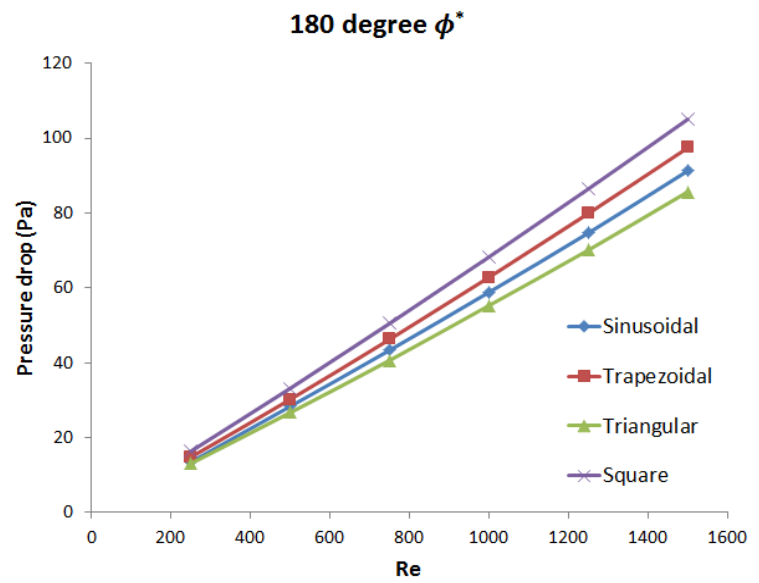

(e)

Fig. 10 Pressure drop (Pa) variation for different geometries at different $\phi^{*}$ : (a) $0^{\circ}$ (b) $45^{\circ}$ (c) $90^{\circ}$ (d) $135^{\circ}$ (e) $180^{\circ}$

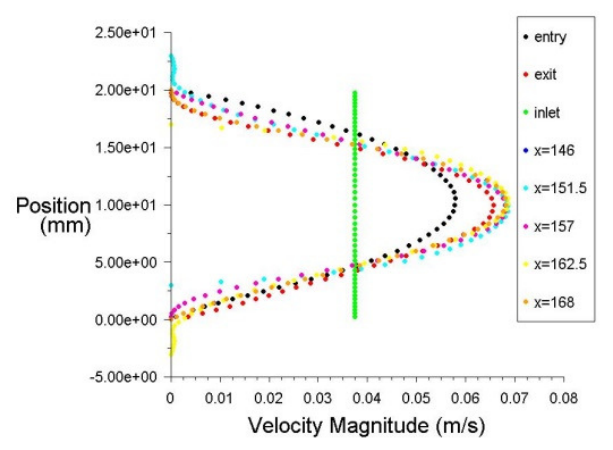

(a)

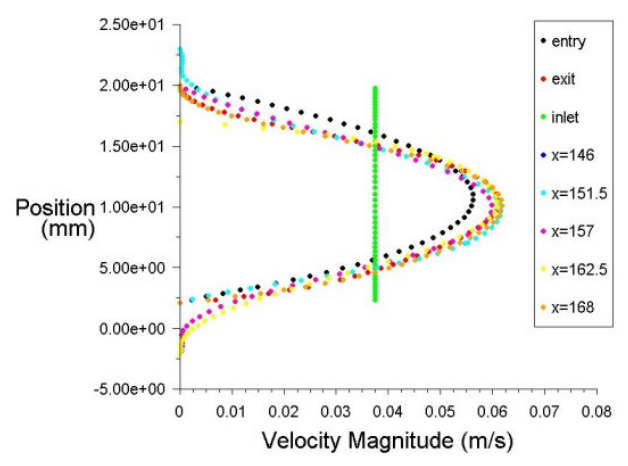

(b) 


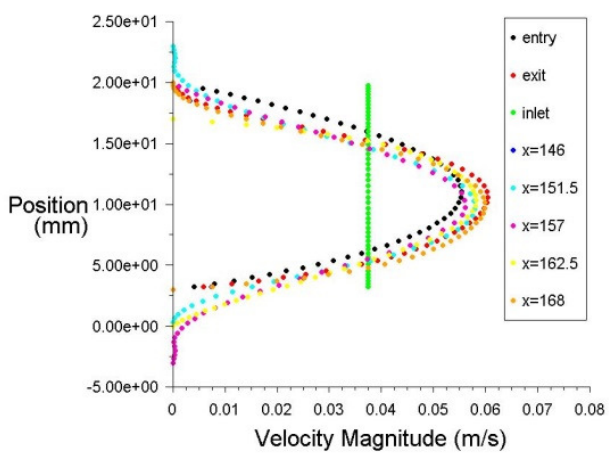

(c)

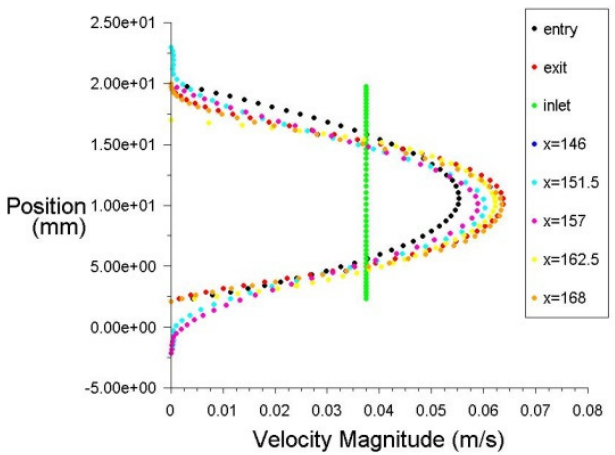

(d)

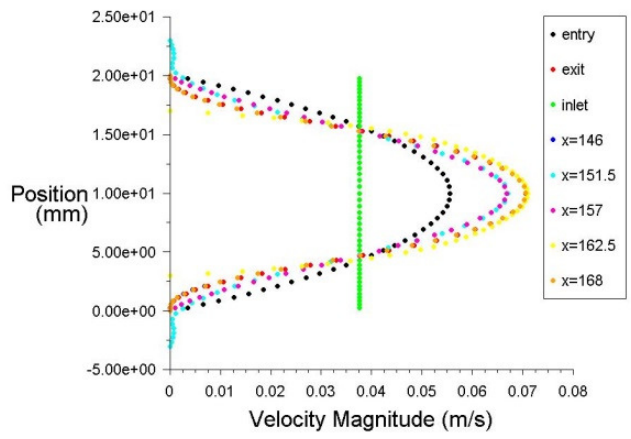

(e)

Fig. 11 Velocity magnitude plots for sinusoidal channel at different $\phi^{*}$ : (a) $0^{\circ}$ (b) $45^{\circ}$ (c) $90^{\circ}$ (d) $135^{\circ}$ (e) $180^{\circ}$

\section{CONCLUSIONS}

A detailed analysis pertaining to the flow of a nanofluid through wavy channel(s) is reported in the present work. The analysis of the effect of nanoparticle size and concentration on heat transfer enhancement for Au based nanofluid shows the enhancement to be significant for higher Reynolds number and also the effect of particle size and concentration is more predominating at higher Reynolds number. The effect of geometrical parameters (amplitude and $\phi^{*}$ ) on heat transfer enhancement and pressure drop characteristics have been studied for four different wavy shapes (sinusoidal, triangular, trapezoidal and square) of the channel with $\mathrm{Au}$-water nanofluid with $5 \%$ concentration and $50 \mathrm{~nm}$ nanoparticle size. By increasing the amplitude, the results show a higher heat transfer enhancement but at the cost of increase in pressure drop. The selection of the required geometry is based on the particular needs and conditions and there is a tradeoff between heat transfer enhancement and pressure drop. The effect of phase difference between the top and the bottom wavy walls for all the four shapes (sinusoidal, trapezoidal, triangular and square) are compared. The analysis suggests that $90^{\circ}$ phase shift of the wavy channel is not favorable for heat dissipating devices. To conclude, the favorable results for heat transfer enhancement are obtained for triangular channel followed by sinusoidal at $45^{\circ}, 90^{\circ}$ and $135^{\circ}$ phase shift. But if pressure drop is not of much consideration as compared to heat transfer enhancement then square channel at $180^{\circ}$ and trapezoidal channel at $0^{\circ}$ can be considered for getting maximum heat transfer rate.

\section{ACKNOWLEDGEMENTS}

The authors gratefully acknowledge NBHM, Govt. of India for sanctioning a major research project under the grant number 2/48(19)/2012/NBHM(R.P.)/R\&D II/9137.

\section{NOMENCLATURE}

a wavy amplitude $(\mathrm{mm})$

$\mathrm{C}_{\mathrm{p}} \quad$ specific heat $(\mathrm{J} / \mathrm{kg} \mathrm{K})$

d molecular diameter $(\mathrm{nm})$

$\mathrm{D}_{\mathrm{h}} \quad$ hydraulic diameter $(\mathrm{mm})$

$\mathrm{H} \quad$ half of channel height $(\mathrm{mm})$

$\mathrm{K}$ thermal conductivity $\left(\mathrm{W} / \mathrm{m}^{\circ} \mathrm{C}\right)$

$\mathrm{Nu} \quad$ Nusselt number

$\mathrm{P} \quad$ static pressure $(\mathrm{Pa})$

Pe Peclet number

Pr Prandtl number

$\Delta P \quad$ pressure drop $(\mathrm{Pa})$

Re Reynolds number

$\mathrm{t}$ time (s)

$\mathrm{T} \quad$ temperature $\left({ }^{\circ} \mathrm{C}\right)$

$\mathrm{x}, \mathrm{y} \quad$ 2D Cartesian coordinates (m)

$\mathrm{X}, \mathrm{Y}$ dimensionless cartesian coordinate

$\mathrm{u}, \mathrm{v} \quad$ velocity components $(\mathrm{m} / \mathrm{s})$

$\mathrm{U}, \mathrm{V}$ dimensionless velocity component

Greek Symbols

$\alpha \quad$ thermal diffusivity $\left(\mathrm{m}^{2} / \mathrm{s}\right)$

$\lambda \quad$ wavelength (mm) 
$\phi \quad$ volume fraction of nanoparticles (\%)

$\phi^{*} \quad$ phase angle between top and bottom wavy walls

$\mu \quad$ dynamic viscosity (N.S $\left./ \mathrm{m}^{2}\right)$

$\rho \quad$ density of the fluid $\left(\mathrm{kg} / \mathrm{m}^{3}\right)$

$\tau \quad$ dimensionless time

$\theta \quad$ dimensionless temperature

Subscripts

e end point of wavy wall

eff effective

f base fluid

in inlet

1 average value

nf nanofluid

$\mathrm{p} \quad$ particles

S starting point of wavy wall

w wall

$\mathrm{x}$ local value

\section{REFERENCES}

Arani A.A.A., Amani J., 2012, "Experimental Study on the Effect of $\mathrm{TiO}_{2}$-Water Nanofluid on Heat Transfer and Pressure Drop," Experimental Thermal and Fluid Science, 42, pp. 107-115.

http://dx.doi.org/10.1016/j.expthermflusci.2012.04.017

Ahmed M.A., Shuaib N.H., Yusoff M.Z., Al-Falahi A.H., 2011, "Numerical Investigations of Flow and Heat Transfer Enhancement in a Corrugated Channel Using Nanofluid," International Communications in Heat and Mass Transfer, 38 (10), pp. 1368-1375.

http://dx.doi.org/10.1016/j.icheatmasstransfer.2011.08.013

Ahmed M.A., Shuaib N.H., Yusoff M.Z., 2012, "Numerical Investigations on the Heat Transfer Enhancement in a Wavy Channel Using Nanofluid," International Journal of Heat and Mass Transfer, 55 (21-22), pp. 5891-5898.

http://dx.doi.org/10.1016/j.ijheatmasstransfer.2012.05.086

Ahmed M.A., Yusoff M.Z., Shuaib N.H., 2013, "Effects of Geometrical Parameters on the Flow and Heat Transfer Characteristics in Trapezoidal-Corrugated Channel Using Nanofluid," International Communications in Heat and Mass Transfer, 42, pp. 69-74.

http://dx.doi.org/10.1016/j.icheatmasstransfer.2012.12.012

Arnida, Janat-Amsbury M.M., Ray A., Peterson C.M., Ghandehari H., 2011, "Geometry and Surface Characteristics of Gold Nanoparticles Influence Their Biodistribution and Uptake by Macrophages," European Journal of Pharmaceutics and Biopharmaceutics, 77(3), pp. 417-423.

http://dx.doi.org/10.1016/j.ejpb.2010.11.010

Vatani A., Mohammed H.A, 2013, "Turbuent Nanofluid Nanofluid over Periodic Rib-Grooved Channel," Engineering Application of Computational Fluid Mechanics, 7(3), pp. 369-381.

http://scival-expert.utm.my/pubDetail.asp?t=pm\&id=84882303327\&

Bogliotti N., Oberleitner B., Di-Cicco A., Schmidt F., Florent J.C., Semetey V, 2011, "Optimizing the Formation of Biocompatible Gold Nanorods for Cancer Research: Functionalization, Stabilization and Purification," Journal of Colloid and Interface Science, 357(1), pp. 7581.

http://dx.doi.org/10.1016/j.jcis.2011.01.0 53

Brinkman H.C., 1952, "The Viscosity of Concentrated Suspensions and Solution," Journal of Chemical Physics, 20, 571-581.

http://dx.doi.org10.1063/1.1700493
Davarnejad R., Barati S., Kooshki M., 2013, "CFD Simulation of the Effect of Particle Size on the Nanofluids Convective Heat Transfer in the Developed Region in a Circular Tube," Springer Plus, 2, pp. 192198.

http://dx.doi.org/10.1186/2193-1801-2-192

Fakoor-Pakdaman M., Akhavan-Behabadi M.A., Razi P., 2013, "An Empirical Study on the Pressure Drop Characteristics of Nanofluid Flow Inside Helically Coiled Tubes," International Journal of Thermal Sciences, 65, pp. 206-213. http://dx.doi.org/10.1016/j.ijthermalsci.2012.10.014

Fluent 6.3 User's Guide, Fluent Inc., 2006

Hamilton R.L., Crosser O.K., 1962, "Thermal Conductivity of Heterogeneous Two-Component Systems," Industrial \& Engineering Chemistry Fundamentals, 1(3), pp. 187-191.

http://dx.doi.org/10.1021/i160003a005

Heidary H., Kermani M.J., 2010, "Effect of Nano-Particles on Forced Convection in Sinusoidal-Wall Channel," International Communications in Heat and Mass Transfer, 37(10), pp. 1520-1527. http://dx.doi.org/10.1016/j.icheatmasstransfer.2010.08.018

Hossain M.Z. and Sadrul Islam A.K.M., 2007, "Numerical Investigation of Fluid Flow and Heat Transfer Characteristics in Sine, Triangular, and Arc-Shaped Channels," Thermal science, 11(1), pp. 1726.

http://dx.doi.org/10.2298/TSCI0701017H

Hussein A.M., Sharma K.V., Bakar R.A., Kadirgama K., 2013, “A Review of Forced Convection Heat Transfer Enhancement and Hydrodynamic Characteristics of a Nanofluid," Renewable and Sustainable Energy Reviews, 29, pp. 734-743.

http://dx.doi.org/10.1016/j.rser.2013.08.014

Kalteh M., Abbassi A., Saffar-Avval M., Harting J., 2011, "EulerianEulerian Two-Phase Numerical Simulation of Nanofluid Laminar Forced Convection in a Microchannel," International Journal of Heat and Fluid Flow, 32(1), pp. 107-116.

http://dx.doi.org/10.1016/j.ijheatfluidflow.2010.08.001

Kalteh M., 2013, "Investigating the Effect of Various Nanoparticle and Base Liquidtypes on the Nanofluids Heat and Fluid Flow in a Microchannel," Applied Mathematical Modelling, 37(18-19), pp. 86008609.

http://dx.doi.org/10.1016/j.apm.2013.03.067

Kheram M.A., 2011, "Numerical Study on Convective Heat Transfer for Water-Based Alumina Nanofluids," International Journal of Nano Dimension, 1(4), pp. 297-304.

http://www.hindawi.com/journals/stni/2012/928406/

Khoshvaght-Aliabadi M., Hormozi F., Zamzamian A., 2014, "Experimental Analysis of Thermal-Hydraulic Performance of Copper-Water Nanofluid Flow in Different Plate-Fin Channels," Experimental Thermal and Fluid Science, 52, pp. 248-258. http://dx.doi.org/10.1016/j.expthermflusci.2013.09.018

Lotfi R., Saboohi Y., Rashidi A.M., 2010, "Numerical Study of Forced Convective Heat Transfer of Nanofluids: Comparison of Different Approaches," International Communications in Heat and Mass Transfer, 37(1), pp. 74-78. http://dx.doi.org/10.1016/j.icheatmasstransfer.2009.07.013

Maxwell J.C., 1904, Treatise on Electricity and Magnetism, Oxford University Press London. 
Moraveji M.K., Ardehali R.M., Ijam A., 2013, “CFD Investigation of Nanofluid Effects (Cooling Performance and Pressure Drop) in MiniChannel Heat Sink," International Communications in Heat and Mass Transfer, 40, pp. 58-66. http://dx.doi.org/10.1016/j.icheatmasstransfer.2012.10.021

Moraveji M.K., Ardehali R.M., 2013, “CFD Modeling (Comparing Single and Two-Phase Approaches) on Thermal Performance of $\mathrm{Al}_{2} \mathrm{O}_{3}$ Water Nanofluid in Mini-Channel Heat Sink," International Communications in Heat and Mass Transfer, 44, pp. 157-164. http://dx.doi.org/10.1016/j.icheatmasstransfer.2013.02.012

Naphon P., 2009, "Effect of Wavy Plate Geometry Configurations on the Temperature and Flow Distributions," International Communications in Heat and Mass Transfer, 36(9), pp. 942-946.

http://dx.doi.org/10.1016/j.icheatmasstransfer.2009.05.007

Patel H.E., Sundarrajan T., Pradeep T., Dasgupta A., Das S.K., 2005, "A Micro-Convection Model for Thermal Conductivity of Nanofluid," Pramana Journal of Phyics, 65(5), pp. 863-869. http://link.springer.com/article/10.1007\%2FBF02704086

Pehlivan H., Taymaz I., İslamoğlu Y., 2013, "Experimental Study of Forced Convective Heat Transfer in a Different Arranged Corrugated Channel," International Communications in Heat and Mass Transfer, 46, pp. 106-111. http://dx.doi.org/10.1016/j.icheatmasstransfer.2013.05.016

Rohsenow W.M., Hartnett J.P, Cho Y.I., 1998, Handbook of Heat Transfer, 3rd edition, McGraw-Hill, New York.

Santra A.K., Sen S., Chakraborty N., 2009, "Study of Heat Transfer Due to Laminar Flow of Copper-Water Nanofluid through Two Isothermally Heated Parallel Plates," International Journal of Thermal Sciences, 48(2), pp. 391-400.

http://dx.doi.org/10.1016/j.ijthermalsci.2008.10.004
Vanaki Sh.M., Mohammed H.A., Abdollahi A., Wahid M.A., 2014, "Effect of Nanoparticle Shapes on the Heat Transfer Enhancement in a Wavy Channel with Different Phase Shifts," Journal of Molecular Liquids, 196, pp. 32-42. http://dx.doi.org/10.1016/j.molliq.2014.03.001

Wang C.C., Chen C.K., 2002, "Forced Convection in a Wavy-Wall Channel," International Journal of Heat and Mass Transfer, 45(12), pp. 2587-2595. http://dx.doi.org/10.1016/S0017-9310(01)00335-0

Xuan Y., Roetzel W., 2000, “Conceptions for Heat Transfer Correlation of Nanofluid," International Journal of Heat Mass Transfer, 43(19), pp. 3701-3707.

http://dx.doi.org/10.1016/S0017-9310(99)00369-5

Yang Y.T., Wang Y.H., Tseng P.K., 2014, "Numerical Optimization of Heat Transfer Enhancement in a Wavy Channel Using Nanofluids," International Communications in Heat and Mass Transfer, 51, pp. 917.

http://www.sciencedirect.com/science/article/pii/S073519331300239X

Yin J., Yang G., Li Y., 2012, "The Effects of Wavy Plate Phase Shift on Flow and Heat Transfer Characteristics in Corrugated Channel," Energy Procedia, 14, pp. 1566 - 1573.

http://dx.doi.org/10.1016/j.egypro.2011.12.1134

Youssef M.S., Aly A.A., Zeidan E.S.B., 2012, "Computing the Pressure Drop of Nanofluid Turbulent Flows in a Pipe Using an Artificial Neural Network Model," Open Journal of Fluid Dynamics, 2, pp. 130-136 http://dx.doi.org/10.4236/ojfd.2012.24013

Yu W., Choi S.U.S., 2003, "The Role of Interfacial Layers in the Enhanced Thermal Conductivity of Nanofluids: A Renovated Maxwell Model," Journal of Nanoparticle Research, 5(1-2), pp. 167-171. http://link.springer.com/article/10.1023\%2FA\%3A1024438603801 